\title{
Health Effects of Coal: A Long-Run Relationship Assessment of Coal Production and Respiratory Health in Kazakhstan
}

\author{
Almaz Akhmetov ${ }^{1,2}$ \\ ${ }^{1}$ ENCA Management, Yessik, Kazakhstan \\ ${ }^{2}$ Orizon Consulting Services, McLean, VA, USA \\ Correspondence: Almaz Akhmetov, ENCA Management, Pobedy Str., 7, Yessik, 040400, Kazakhstan. Tel: \\ 7-777-228-6214. E-mail: al_akhmetov@yahoo.co.uk
}

Received: November 4, 2014 Accepted: November 9, $2014 \quad$ Online Published: November 23, 2014

doi:10.5539/eer.v4n3p138

URL: http://dx.doi.org/10.5539/eer.v4n3p138

\begin{abstract}
Respiratory diseases, like asthma and other chronic obstructive pulmonary disease, claim over 50 thousand lives annually in Kazakhstan according to national statistics (The Agency of Statistics of the Republic of Kazakhstan, 2011). This study applies econometric methods to examine the relationship between the coal industry and the respiratory health in Kazakhstan during the country's independency period using annual national data. The study investigates long-term equilibrium and short-term dynamics of coal production and respiratory diseases in Kazakhstan by applying the Vector Error Correction Model (VECM). The empirical results show that the respiratory diseases appear to be elastic relative to the coal production, and the strong long-run and short-run Granger causality running from coal production to respiratory diseases. The presence of causal relationship could be useful to define effective policies to reduce the health effects of coal industry in Kazakhstan.
\end{abstract}

Keywords: Kazakhstan, coal industry, respiratory health, granger causality, air pollution

\section{Introduction}

About 5 million people in Kazakhstan live in an area with polluted air, and the cost of health damage from the air pollution reaches 70.8 USD per person, or 76.2 USD per ton of air pollutant (Zubov, 2007). The major source of the air pollution in Kazakhstan is the energy sector, which is primarily fuelled by coal. Coal is the most abundant fossil fuel on Earth, and Kazakhstan's reserves make up almost 4\% of the world's total coal reserves (BP, 2011). Coal is being actively replaced by cleaner sources of energy worldwide and Kazakhstan is among countries implementing a low-carbon development strategy and designing a law aimed at promoting renewable energy. Despite this fact, Kazakhstan is most likely to maintain the current status quo with regards to the coal consumption due to significantly low cost of extraction and transportation of the coal which makes it a dominant source of energy in Kazakhstan.

Coal accounts for about $44 \%$ of total primary energy demand and electricity production as well as $80 \%$ of the total power production in Kazakhstan (IEA, 2010). With exception of western Kazakhstan, where oil and gas are the main products used for the power production, in all other parts of the country coal is the primary source for the power generation and space heating. Approximately $60 \%$ of the coal in Kazakhstan is used as the steam coal at the power plants, $14 \%$ of coal is used to heat space and water by residential sector and $26 \%$ of coal mined in Kazakhstan is exported to other countries, primarily to Russia and Kyrgyz Republic (Concept of Coal Industry Development of Kazakhstan until 2020, 2008). The electricity and heat are co-generated through the use of the steam coal at large scale State District Power Stations (SDPS) and Combined Heat and Power (CHP) plants. The largest coal producers are the structural units of large power and metallurgical companies. The district boiler stations burn coal to produce heat for the centralized residential heating system.

The general characteristics of Kazakhstani coal are high calorific properties and low sulfur content. However, the high ash content of the coal not only lowers its competitiveness in the world market, but also affects the stability of the combustion process and the reliability of furnaces at the power plants. This results in increased emissions of carbon monoxide, nitrogen oxides and sulfur oxides (Bukhman, 2003). In the life cycle of coal consumption, pre-combustion emissions of hazardous substance to air contribute only $0.2 \%$ of the total pollution, while the rest of the air pollution is created during the combustion process (Akhmetov et al., 2012). However, soil and water 
pollution is not accounted for in the existing studies in Kazakhstan.

Due to the unequal distribution of the reserves of fossil fuel in Kazakhstan, there are areas in the country where coal is the only source of energy, particularly in the heating season. This fact also produces large seasonal cost variations in such areas. Individual residences, where no centralized heating system is available, burn coal in self-made coal stove to heat their homes. Coal combustion in the residential sector for space and water heating is not inventoried as point sources. However, this process is the main source of the indoor air pollution in coal-dependent regions of Kazakhstan. Most domestic coal stoves are of poor quality as shown in Figure 1.

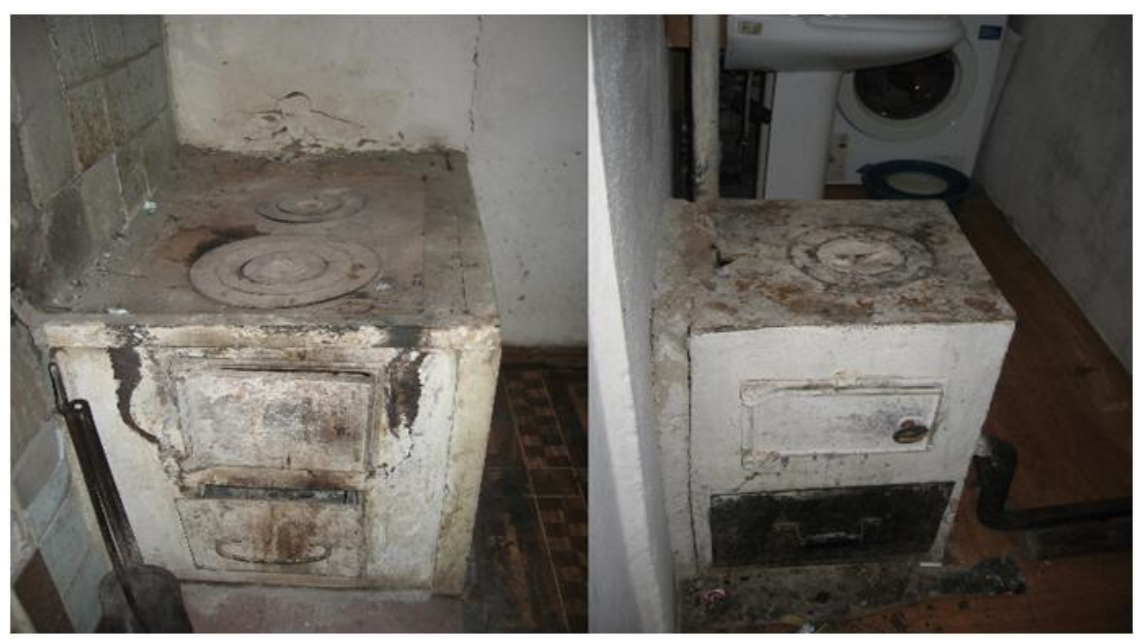

Figure 1. Typical home-made coal stoves used for space heating in rural areas of Kazakhstan without centralized heating system

Visible cracks and dirt deposits on the stoves may indicate the presence of indoor air pollution. Furthermore, the low temperature of the combustion and short chimneys may indicate that air pollution disperses downward and increases near the ground. Hence, the pollution is localized and causes a degradation of the regional environment.

Respiratory diseases are the most commonly diagnosed diseases in Kazakhstan, and account for $42 \%$ of the total registered diseases (The Agency of Statistics of the Republic of Kazakhstan, 2011). The statistics indicate that respiratory disease causes substantial burden on the economy and health of the country. In 2004, the disability-adjusted life year (DALY), an overall disease burden measure, due to non-communicable respiratory diseases was the $9^{\text {th }}$ biggest in the world, or 1.6 times bigger than world average (WHO, 2009). Although there are different causes of respiratory diseases, the coal industry is very often the main cause in regions, where coal is the main fuel (Lockwood, 2012, pp. 111-127).

The existing research on air pollution and health deterioration are mainly regional and city level studies (Bowen et al., 1995; Koop et al., 2010; Mennis, 2005; Sheppard, et al. 1999; Sobral, 1989). The studies indicate a strong relationship between air pollution and induced health problems in the short- and long-term. The existing studies (Gelobter, 1992; Gianessi et al., 1979) also support the evidence of the relationship between health conditions and air quality. Furthermore, studies on indoor air pollution impact on health in developing countries (Dasgupta et al., 2006; Smith \& Mehta, 2003) also prove the connection between the variables. Most of the regional and national studies have identified that poor people, ethnic minorities, children and elderly people are most vulnerable to air pollution impacts. Ren \& Tong (2008) made a thorough overview of recent epidemiology research developments and methodological issues on health effects of ambient air pollution.

Health impacts of coal industry from various locations worldwide are comprehensively described by Finkelman et al. (2002). The examples provided in the study suggest that coal-related health problems are becoming serious issue in emerging and developing countries, where cheap coal is the main fuel for the economies. Generally, the studies about the coal industry impact on health and well-being of people could be divided by life cycle stages of coal: mining and storage (Ghose \& Majee, 2000; Hendryx, 2009; Morrice \& Colagiuri, 2013), combustion at the power plants (Penney et al., 2009; Riekert \& Koch, 2011) and full life cycle (Castelden et al., 2011; Epstein et al., 2011). 
The literature on health effects of the coal industry in Kazakhstan primarily describes the health status of the coal miners (Terekhin \& Pichkhadze, 1991). Dahl \& Kuralbayeva (2001) indicated that the coal production and use are the main causes for the environmental degradation in the industrial regions of Kazakhstan.

Kenessariyev et al. (2013) estimated the mortality attributed to air pollution caused by total suspended particles in 11 cities across Kazakhstan. The study utilizes a log-linear concentration response function to estimate air pollution attributed mortality with other mortality causes in the country. The study revealed that the premature mortality caused by air pollution in Kazakhstan is significantly higher than in Russia and Ukraine. It was suggested that coal consumption was the main cause of such result. Furthermore, the results indicated that Almaty had the highest number of deaths attributed to air pollution in Kazakhstan. Despite the limitations of the study (such as significant uncertainties, use of total mortality without looking at the causes and not including other pollution compounds) it laid a basis for a scientific foundation for further studies on air pollution effects in Kazakhstan. To the best knowledge of the author, there is no research about the possible impact of the coal production and use on the respiratory health in Kazakhstan.

The empirical analysis presented here helps to define which factor is the main cause of growing number of respiratory diseases in Kazakhstan. The variables tested are production of commonly produced fossil fuel and the number of automobiles in Kazakhstan. In this study, fossil fuel production data is used instead of consumption data as coal industry has negative impact on respiratory health throughout the entire life cycle.

\section{Method}

The empirical assessment is based on testing long-term relationship between registered respiratory disease instances and production of different fossil fuels (coal, oil and natural gas) and number of automobiles in Kazakhstan, while utilization of the Vector Error Correction Model (VECM) helps to define the short-term dynamics of the variables.

\subsection{Data}

This study collects annual data on total respiratory diseases, coal production, oil production, natural gas production and number of automobiles for the period between 1990 and 2009. The data source for respiratory disease is the medical statistics database developed by MedInform Ltd. (MedInform Ltd., 2014). Information on oil and natural gas production is derived from the BP Statistical Review of World Energy 2011 (BP, 2011), while data on coal production is taken from the Agency of Statistics of the Republic of Kazakhstan (The Agency of Statistics of the Republic of Kazakhstan, 2011). Summary statistics of variables used in the study are given in Table 1.

Table 1. Summary statistics of variables, 1990-2009

\begin{tabular}{lccc}
\hline Variable & Mean & SD & CV (\%) \\
\hline Total respiratory diseases & $4,220,490.95$ & $639,033.59$ & 15.14 \\
Coal production (thousand tons) & $92,918.61$ & $21,105.11$ & 22.71 \\
Oil production (million tons) & 41.55 & 19.90 & 47.91 \\
${\text { Natural gas production (billion } \mathrm{m}^{3} \text { ) }}_{\text {Number of automobiles (thousand) }}$ & 9.51 & 4.64 & 48.81 \\
Nus.39 & 585.80 & 34.68 \\
\hline
\end{tabular}

Note. $\mathrm{SD}$ is standard deviation; $\mathrm{CV}$ is the coefficient of variation.

The trends of time series shown in Figure 2 and indicate steady decline in all series from the beginning in 1990 to almost the end of 1990s and start to increase in 2000, with natural gas production exhibiting the most related variation and respiratory disease exhibiting the least related variation as displayed in Table 1. Oil and natural gas production for export is the main source of the economic growth in Kazakhstan and has significantly increased since 1990, while coal production volumes are still lower than in the pre-independence period (1990-1991). About $50 \%$ of natural gas and almost $90 \%$ of all oil produced in Kazakhstan go for export (BP, 2011), while coal is predominantly for domestic use. Growing population wealth resulted in a significant increase of the number of cars in the $21^{\text {st }}$ century, and number of total diagnosed respiratory diseases has been steadily increasing too since 2000. 


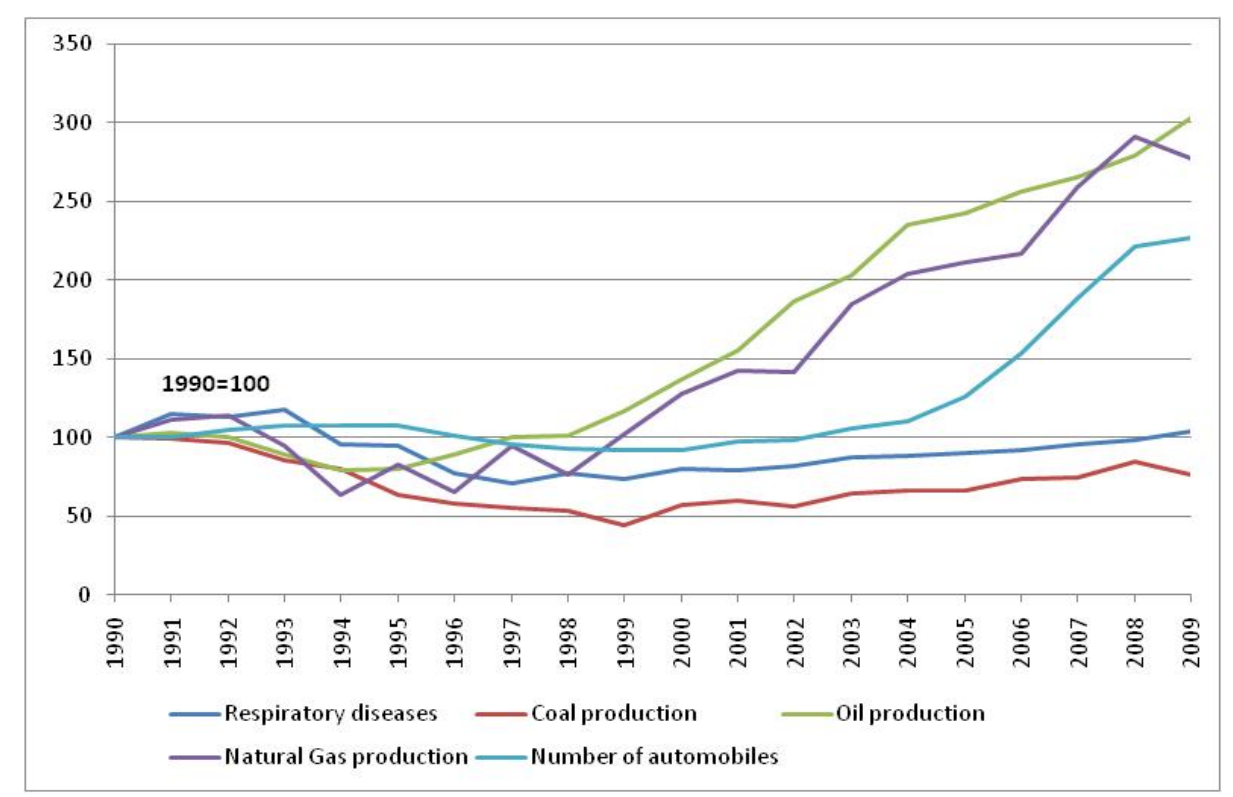

Figure 2. The series plots of total respiratory diseases, fossil fuels production (by type) and number of cars in Kazakhstan, 1990-2009

\subsection{Methodology}

For testing purposes, all data was converted into natural logarithms and the results can be interpreted in growth terms. The analysis is performed using ordinary regression analysis as follows:

$$
\begin{aligned}
& L R D_{t}=\beta_{1}+\beta_{2} L C P_{t}+u_{t} \\
& L R D_{t}=\beta_{3}+\beta_{4} L O P_{t}+u_{t} \\
& L R D_{t}=\beta_{5}+\beta_{6} L G P_{t}+u_{t} \\
& L R D_{t}=\beta_{7}+\beta_{8} L A_{t}+u_{t}
\end{aligned}
$$

where $L R D_{t}, L C P_{t}, L O P_{t}, L G P_{t}$ and $L A_{t}$ represent natural logarithms of total respiratory diseases, coal production, oil production, natural gas production and number of automobiles for year $t$ respectively. This step allows to select the independent variable that creates long-term equilibrium with dependent variable $L R D$. In other words, which of the causes of air pollution has the biggest impact on respiratory diseases in the long-term?

In order to test short-run dynamics of the variables, the VECM is utilized. The analysis is performed in four steps:

a) Verification of the order of the integration of the variables as the co-integration test is only valid for variables of the same order of integration. The Augmented-Dickey-Fuller (ADF) (Said \& Dickey, 1984) and Kwiatkowski-Phillips-Schmidt-Shin (KPSS) (Kwiatkowski et al., 1992) tests are used for the purpose. While ADF test is a test for a unit root, KPSS test is designed on the basis of the null hypothesis that a series is stationary.

b) When all of the series are integrated at the same order, the Johansen maximum likelihood method (Johansen, 1991 ) is used to test the co-integration between the variables. The co-integration of variables indicates the presence of long-run equilibrium relationship between the variables.

c) The VECM is used to correct disequilibrium in the co-integrated relationship by means of error-correction term (ECT), as well as test for presence and direction of long- and short-run Granger causality among co-integrated variables. The VECM for Eq. (1) is specified as follows:

$$
\begin{aligned}
& \Delta L R D_{t}=\gamma_{10}+\sum_{i=1}^{m_{1}} \gamma_{11 i} \Delta L R D_{t-i}+\sum_{i=1}^{n_{1}} \gamma_{12 i} \Delta L C P_{t-i}+\delta_{1} \mathrm{ECT}_{\mathrm{t}-1}+\mu_{1 \mathrm{t}} \\
& \Delta L C P_{t}=\gamma_{20}+\sum_{i=1}^{m_{2}} \gamma_{21 i} \Delta L R D_{t-i}+\sum_{i=1}^{n_{2}} \gamma_{22 i} \Delta L C P_{t-i}+\delta_{2} \mathrm{ECT}_{\mathrm{t}-1}+\mu_{2 \mathrm{t}}
\end{aligned}
$$

where

$$
E C T_{t-1}=L R D_{t-1}-\alpha_{0}-\alpha_{1} \mathrm{LCP}_{\mathrm{t}-1}
$$


The sign $\Delta$ is the first-difference operator; the optimal lag lengths $m_{i}$ and $n_{i}$ are determined using Akaike information criterion (AIC); and coefficients $\delta_{1}$ and $\delta_{2}$ measure the speed of return to equilibrium of the variables $L R D$ and $L C P$ respectively.

d) In the last step, the quality and robustness of the VECM model presented in Eqs. 5-7 is assessed. Known problem with the AIC-based VECM model is the possible model mis-specification caused by unstable parameters (Narayan \& Smith, 2005; Hsiao-Tien et al., 2011). Hence, the parameters consistency needs to be addressed by using the cumulative sum of recursive residuals (CUSUM) and the CUSUM of square (CUSUMSQ) tests (Brown et al., 1975).

\section{Results}

The results of regression analysis indicate that coal production has a much greater impact on respiratory diseases than other variables. Coal production contributed to the increase of the respiratory diseases to $81.8 \%$, followed by road transport which contributed to only $14.2 \%$ of the respiratory diseases as shown in Table 2 .

Table 2. Coefficients of Eq. (1)-(4)

\begin{tabular}{|c|c|c|c|c|c|c|c|}
\hline & \multicolumn{7}{|c|}{ Independent variables } \\
\hline & $\mathrm{LCP}$ & LOP & LGP & LA & Intercept & $\mathrm{R}^{2}$ & $95 \% \mathrm{CI}$ \\
\hline Eq. (1) & $\begin{array}{l}0.603 * * * \\
(8.980)\end{array}$ & & & & $\begin{array}{l}8.365 * * * \\
(10.916)\end{array}$ & 0.818 & $0.462-0.744$ \\
\hline Eq. (2) & & $\begin{array}{l}0.007 \\
(0.089)\end{array}$ & & & $\begin{array}{l}15.221 * * * \\
(55.916)\end{array}$ & 0.001 & $-0.150-0.163$ \\
\hline Eq. (3) & & & $\begin{array}{l}0.059 \\
(0.823)\end{array}$ & & $\begin{array}{l}15.117 * * * \\
(95.425)\end{array}$ & 0.036 & $-0.09-0.211$ \\
\hline Eq. (4) & & & & $\begin{array}{l}0.198 \\
(1.724)\end{array}$ & $\begin{array}{l}13.784 * * * \\
(16.260)\end{array}$ & 0.142 & $-0.043-0.439$ \\
\hline
\end{tabular}

Note. Numbers in parenthesis indicate t-statistics. *** indicate a $1 \%$ level of significance. CI - confidence interval.

The insignificance of the oil and natural gas impact on respiratory disease could be explained by the fact that the fossil fuel is the primary source of the export and coal is the main domestic fuel of the economy. Furthermore, it is likely that the variable LA is more significant for urban areas.

The time series properties of LRD and LCP are checked through both ADF and KPSS unit root tests. The results of both tests indicate that both series appear to contain unit root in their levels but stationary in their first difference, indicating that they are integrated at order one i.e. $I(1)$ as displayed in Table 3.

Table 3. Results of unit root tests

\begin{tabular}{lllll}
\hline \multicolumn{3}{l}{ ADF test } & \multicolumn{2}{l}{ KPSS test } \\
\hline Variable & Level & $1^{\text {st }}$ difference & Level & $1^{\text {st }}$ difference \\
LRD & 0.745 & $-2.577^{* *}$ & $0.569^{* * *}$ & 0.070 \\
LCP & -0.570 & $-3.793 * * *$ & $0.322^{* * *}$ & 0.072 \\
\hline
\end{tabular}

Note. $* *$ and $* * *$ indicate that the null hypothesis is rejected at $5 \%$ and $1 \%$ level respectively. The optimal lag lengths are selected using AIC.

The results of Johansen's co-integration test the presence of co-integration between the variables as seen in Table 4. The results indicate that there is a long-run equilibrium relationship between respiratory diseases and coal production, and the normalized co-integrating vector with respect to LRD is $(1,0.603)$ as in Table 2 . This implies that $1 \%$ increase in coal production results in $0.603 \%$ increase in respiratory diseases. Hence, the respiratory diseases appear to be coal production elastic. The evidence of co-integration also indicates that the estimated model in Eq. 1 does not lead to spurious regression results, and the estimated parameters are super-consistent. 
Table 4. Results of Johansen's co-integration test

\begin{tabular}{llllll}
\hline \multicolumn{6}{l}{ Variables: LRD and LCP } \\
\hline Eigenvalue & Trace & $5 \%$ critical & Max. Eigen & $5 \%$ critical & Number of \\
& Statistic & value & Statistic & value & co-integration \\
0.946 & $47.528^{* *}$ & 15.495 & $43.777^{* *}$ & 14.264 & None \\
0.221 & 3.751 & 3.841 & 3.751 & 3.842 & At most 1
\end{tabular}

Note. The optimal lag lengths are selected using AIC. ** indicates the rejection of a null hypothesis at $5 \%$ level of significance.

The existence of co-integration between the variables indicates that Granger causality exists at least in one direction (Engle \& Granger, 1987). However, it does not indicate the direction of causality. The VECM helps to define the direction of causal relationship. The short-run F-statistics, long-run t-statistics and joint F-statistics for Eqs. 5-7 are reported in Table 5.

Table 5. Results of causality tests

\begin{tabular}{|c|c|c|c|c|c|}
\hline \multirow{3}{*}{ Dependent variables } & \multicolumn{5}{|c|}{ Source of causation } \\
\hline & \multicolumn{2}{|c|}{ Short-run $F$-statistics } & \multirow{2}{*}{$\begin{array}{l}\text { Long-run } t \text {-statistics } \\
\text { ECT }\end{array}$} & \multicolumn{2}{|c|}{ Joint short-run and long-run $F$-statistics } \\
\hline & $\Delta \mathrm{LRD}$ & $\Delta \mathrm{LCP}$ & & $\Delta \mathrm{LRD} / \mathrm{ECT}$ & $\Delta \mathrm{LCP} / \mathrm{ECT}$ \\
\hline$\Delta \mathrm{LRD}$ & & $4.755^{* *}$ & $-3.918 * *$ & & $9.471 * *$ \\
\hline$\triangle \mathrm{LCP}$ & $4.211 *$ & & -1.778 & $4.018^{*}$ & \\
\hline
\end{tabular}

Note. The optimal lag length is four. * and ** indicate $10 \%$ and $5 \%$ level of significance respectively.

The short-run dynamics suggest bidirectional causality from coal production to respiratory diseases and vice-versa. However, the significance of the causal relationship from coal production to respiratory diseases seems to be stronger. The estimated coefficients for ECT indicate the presence of unidirectional causality from coal production to respiratory diseases in the long-run. The joint statistics indicate Granger endogeneity and presence of strong causality from coal production to respiratory diseases. Significantly higher lag length (4) defined by AIC (the most common lag length for annual time series is one) could be partially explained by the nature of the variables as the development of respiratory diseases requires exposure period to air pollution.

CUSUM and CUSUMSQ statistics plots for the variables LRD and LCP are presented in Figures 3 and 4. As it can be seen, both statistics are well within the critical bounds of 5\% significance. This implies that the estimated coefficients of the VECM model are stable for duration of the estimation period. Hence, the results of the Granger causality tests based on the VECM model can be used for policy decision-making (Hsiao-Tien et al., 2011).
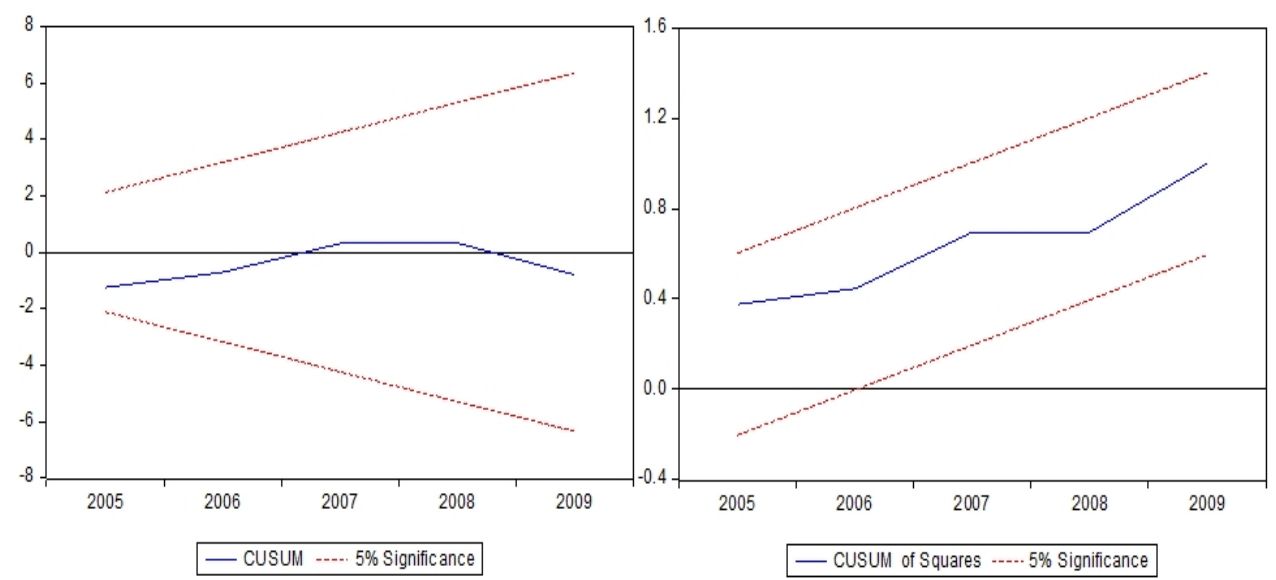

Figure 3. Plot of the CUSUM and CUSUMSQ statistics for a variable LCP 


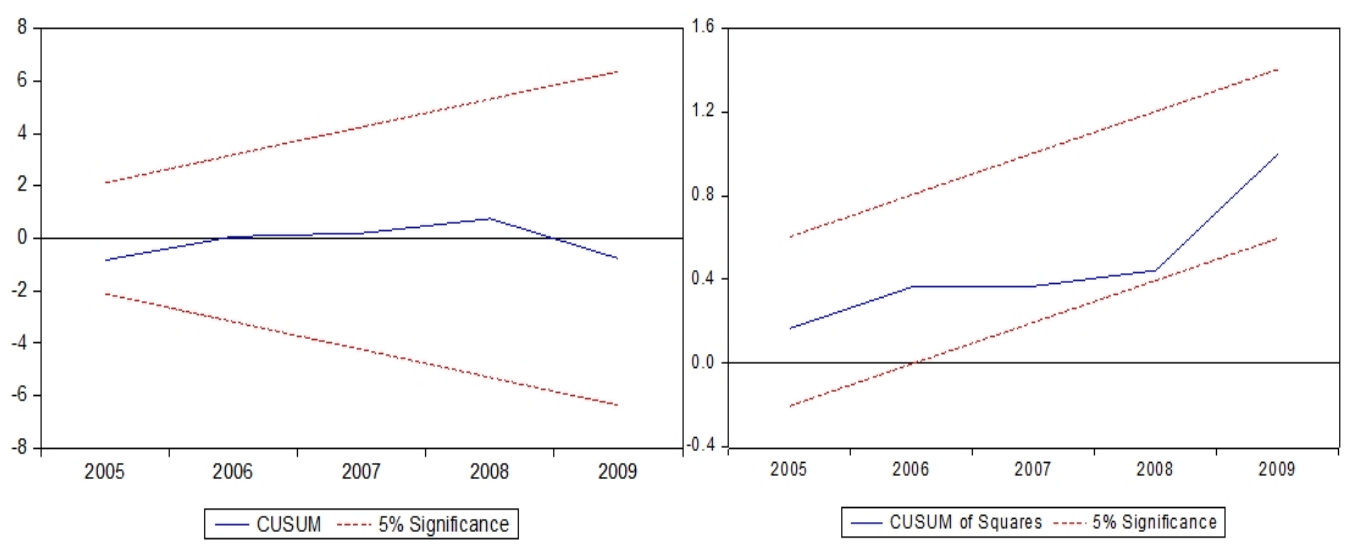

Figure 4. Plot of the CUSUM and CUSUMSQ statistics for a variable LCP

\section{Discussion}

The results of the study indicate that among the main sources of air pollution, coal production has the biggest impact on the growing number of respiratory diseases in Kazakhstan. Furthermore, it found strong short-run and long-run Granger causality running from coal production to respiratory diseases. The results of the study could be used to better define and incorporate relevant environmental policies into Kazakhstan's development strategies.

All policies and initiatives in Kazakhstan, aimed at reducing environmental burden and promoting renewable energy technologies, focus on recent commitments to reduce greenhouse gases (GHG) emissions and the upcoming EXPO 2017. This combination creates an incompatibility between expansion of the coal production and attempts to meet the emissions reduction target. Both reduction of the coal dependency and promotion of green energy are not only necessary to fulfill the GHG commitment, but also vital to health and well-being of the nation. Currently, coal is the cheapest fuel in Kazakhstan, and therefore the most attractive for both industrial and residential users. However, the health costs associated with the use of coal are often unseen, and if these costs are accounted for, coal becomes an expensive fuel.

This is a first attempt to define the relationship between the air pollution caused by coal production and respiratory health in Kazakhstan at a national level. This study should not be treated as epidemiology research on health effects of air pollution. Unlike existing epidemiology studies on the topic, this study does not intend to estimate effects of various air pollutants (particulate matters, ozone or any other pollutant) on health outcomes (health admissions or deaths). The study investigates long-term equilibrium and short-term dynamics of coal production and respiratory diseases in Kazakhstan.

The results of the research prove that the coal industry is not only the main source of global warming pollutants, but also contributes to the environmental burden of respiratory diseases in Kazakhstan. Hence, it verifies the hypothesis of coal industry's significant contribution to overall health risk attributed to air pollution proposed by Kenessariyev et al. (2013). Similar to the study conducted by Kenessariyev et al. (2013), this study also contains a relatively large uncertainty. However, the history of environmental problems in Kazakhstan and the results of the studies call to act based on the precautionary principle - in the absence of scientific certainty of damage of the action, the burden of the proof should be on the industry that stands to profit (Martuzzi \& Tickner, 2004).

Future studies should include analysis on a regional level, given the size of the country and diversity of fuel mix. National level studies provide a broader picture of the issue, however, much of the regional variations remain hidden. Hence, the future studies should include panel data analysis of relationships between fossil fuels combustion and respiratory diseases for all 14 regions of Kazakhstan.

\section{Acknowledgments}

The author would like to thank Foundation on Education Development from Yenbekshikazakh district of Almaty region for a support with research.

\section{References}

Akhmetov, A., Uchiyama, Y., \& Okajima, K. (2012). Life cycle assessment of electricity generation in Kazakhstan. Energy and Fuel Resources of Kazakhstan, March/June Issue, 112-114. 
Bowen, W. M., Salling, M. J., Haynes, K. E., \& Cyran, E. J. (1995). Toward environmental justice: Spatial equity in Ohio and Cleveland. Annals of the Association of American Geographers, 85(4), 641-663. http://dx.doi.org/10.1111/j.1467-8306.1995.tb01818.x

BP. (2011). BP statistical review of world energy 1951-2011. London, UK: BP.

Brown, R., Durbin, J., \& Evans, J. (1975). Techniques for testing the constancy of regression relationships over time. Journal of the Royal Statistical Society, Series B, 37(2), 149-192.

Bukhman, M. (2003). Efficient combustion of coal in Kazakhstan with low emissions of harmful substances into the atmosphere [Technical paper, in Russian]. Retrieved from http://www.unece.org/fileadmin/DAM/ie/capact/ppp/pdfs/buhman_kzkhstn.pdf

Castelden, W. M., Shearman D., Crisp G., \& Finch P. (2011). The mining and burning of coal: Effects on health and the environment. The Medical Journal of Australia, 195(6), 333-335. http://dx.doi.org/10.5694/mja11.10169

Concept of Coal Industry Development of Kazakhstan until 2020 [Government resolution, in Russian] (2008, June 28). No. 2008/644.

Dahl, C., \& Kuralbayeva K. (2001). Energy and the environment in Kazakhstan. Energy Policy, 29(6), 429-440. http://dx.doi.org/10.1016/S0301-4215(00)00137-3

Dasgupta, S., Huq, M., Khaliquzzman, M., Pandey, K., \& Wheeler D. (2006). Indoor air quality for poor families: new evidence from Bangladesh. Indoor Air, 16(6), 426-444. http://dx.doi.org/10.1111/j.1600-0668.2006.00436.x

Engle, R. F., \& Granger, C. W. J. (1987). Co-integration and error correction: representation, estimation and testing. Econometrica, 55(2), 251-276.

Epstein, R., Paul, J., Buonocore, J., Eckerle, K., Hendryx, M., Stout III, B. M., ... Glustrom, L. (2011). Full cost accounting for the life cycle of coal. Annals of the New York Academy of Sciences, 1219, 73-98. http://dx.doi.org/10.1111/j.1749-6632.2010.05890.x

Finkelman, R., Orem, W., Castranova, V., Tatu, C. A., Belkin, H. E., Zheng, B., ... Bates, A. L. (2002). Health impacts of coal and coal use: possible solutions. International Journal of Coal Geology, 50(1-4), 425-443. http://dx.doi.org/10.1016/S0166-5162(02)00125-8

Gelobter, M. (1992). Toward a model of "environmental discrimination". In B. Bryant, \& P. Mohai (Eds), Race and the incidence of environmental hazards: a true time of discourse (pp. 64-81). Boulder, CO: Westview Press.

Ghose, M. K., \& Majee, S. R. (2000). Sources of air pollution due to coal mining and their impacts in Jharia coalfield. Environment International, 26(1-2), 81-85.

Gianessi, L. P., Peskin, H. M., \& Wolff, E. (1979). The distributional effects of uniform air pollution in the United States. Quarterly Journal of Economics, 93(2), 281-301.

Hendryx, M. (2009). Mortality from heart, respiratory, and kidney diseases in coal mining areas of Appalachia. International Archives of Occupational Environmental Health, 82, 243-249. http://dx.doi.org/10.1007/s00420-008-0328-y

Hsiao, T. P., Hsiao, C. Y., \& Yeou, H. Y. (2011). Modeling the CO2 emissions, energy use, and economic growth in Russia. Energy, 36(8), 5094-5100. http://dx.doi.org/10.1016/j.energy.2011.06.004

International Energy Agency (IEA). (2010). Energy balances of non-OECD countries (2010 Edition) (p. 177). Paris, France: OECD/IEA.

Johansen, S. (1991). Estimation and hypothesis testing of cointegration vectors in Gaussian vector autoregressive models. Econometrica, 59(6), 1551-1580.

Kenessariyev, U., Golub, A., Brody, M., Dosmukhametov, A., Amrin, M., Erzhanova, A., \& Kenessary, D. (2013). Human health cost of air pollution in Kazakhstan. Journal of Environmental Protection, 4(8), 869-876. http://dx.doi.org/10.4236/jep.2013.48101

Koop, G., McKitrick, R., \& Tole, L. (2010). Air pollution, economic activity and respiratory illness: evidence from Canadian cities, 1974-1994. Environmental Modelling \& Software, 25(7), 873-885. http://dx.doi.org/10.1016/j.envsoft.2010.01.010

Kwiatkowski, D., Phillips, P. C. B., Schmidt, P., \& Shin, Y. (1992). Testing null hypothesis of stationarity against 
the alternative unit root. Journal of Econometrics, 54, 159-178.

Lockwood, A. H. (2012). The silent epidemic: coal and the hidden threat to health. Cambridge, MA: The MIT Press.

Martuzzi, M., \& Tickner J. A. (2004). Introduction - the precautionary principle: protecting public health, the environment and the future of our children. In M. Martuzzi, \& J. A. Tickner (Eds.), The precautionary principle: protecting public health, the environment and the future of our children (pp. 7-14). Copenhagen, Denmark: World Health Organization Europe.

MedInform Ltd. (2014). Medstat [Medical statistics database, in Russian]. Retrieved from http://medinform.kz/prog.jsp?prog=Medstat

Mennis, J. L. (2005). The distribution and enforcement of air polluting facilities in New Jersey. The Professional Geographer, 57(3), 411-422. http://dx.doi.org/10.1111/j.0033-0124.2005.00487.x

Morrice, E., \& Colagiuri, R. (2013). Coal mining, social injustice and health: a universal conflict of power and priorities. Health \& Place., 19, 74-79. http://dx.doi.org/10.1016/j.healthplace.2012.10.006

Narayan, P. K., \& Smith, R. (2005). Electricity consumption, employment and real income in Australia evidence from multivariate Granger causality test. Energy Policy, 33(9), 1109-1116. http://dx.doi.org/10.1016/j.enpol.2003.11.010

Penney, S., Bell, J., \& Balbus, J. (2009). Estimating the health impacts of coal-fired power plants receiving international financing [Technical report]. Washington, DC: Environmental Defense Fund. Retrieved from http://www.edf.org/sites/default/files/9553_coal-plants-health-impacts.pdf

Ren, C., \& Tong, S. (2008). Health effects of ambient air pollution - recent research development and contemporary methodological challenges. Environmental Health, 7(1), 56-66. http://dx.doi.org/10.1186/1476-069X-7-56

Riekert, J. W., \& Koch, S. F. (2012). Projecting the external cost of a coal-fired power plant: the case of Kusile. Journal of Energy in Southern Africa, 23(4), 52-66. Retrieved from http://www.erc.uct.ac.za/jesa/volume23/23-4jesa-riekert-koch.pdf

Said, S. E., \& Dickey, D. A. (1984). Testing for unit roots in autoregressive-moving average models of unknown order. Biometrika, 71(3), 599-607.

Sheppard, E., McMaster R. B., Leitner H., Elwood, S., \& Gonguo, T. (1999). Examining environmental equity in Hennepin county in Minneapolis. CURA Reporter, 29(3), 1-8.

Smith, K. R., \& Mehta, S. (2003). The burden of disease from indoor air pollution in developing countries: Comparison of estimates. International Journal of Hygiene and Environmental Health, 206(4-5), 279-289. http://dx.doi.org/10.1078/1438-4639-00224

Sobral, H. R. (1989). Air pollution and respiratory diseases in children in Sao Paolo, Brazil. Social Science \& Medicine, 29(8), 959-964. http://dx.doi.org/10.1016/0277-9536(89)90051-8

Terekhin, S. P., \& Pichkhadze, G. M. (1991). The prevalence of primary hypo-vitaminosis among steelmakers and miners of Karaganda region [in Russian]. Health in Kazakhstan, 3, 25-26.

The Agency of Statistics of the Republic of Kazakhstan. (2011). Kazakhstan in the years of independence 1991-2010: statistical compendium [in Russian]. Astana: The Agency of Statistics of the Republic of Kazakhstan.

World Health Organization (WHO). (2009, February). Death and DALY estimates for 2004 by cause for WHO member states. Persons, all ages [Excel spreadsheet]. Retrieved from http://www.who.int/healthinfo/global_burden_disease/estimates_country/en/

Zubov, A. (2007, September 28). Kazakhstan becomes a zone of high ecological risk [in Russian]. Delovoi Kazakhstan, 37, 4.

\section{Copyrights}

Copyright for this article is retained by the author(s), with first publication rights granted to the journal.

This is an open-access article distributed under the terms and conditions of the Creative Commons Attribution license (http://creativecommons.org/licenses/by/3.0/). 